\title{
Implicature, Inference and Cancellability
}

\author{
Michael Haugh \\ School of Languages and Linguistics, Griffith University
}

\begin{abstract}
The standard position in pragmatics to date has been that cancellability is useful way of differentiating implicatures from logical implications, semantic entailments and the like. In recent years, however, there has been considerable debate as to whether implicatures are in fact always cancellable, or indeed whether they are cancellable at all, amongst linguistic pragmaticians and language philosophers. In this chapter, it is suggested that cancellability encompasses a range of actions that play out in different ways depending on whether we are analysing inferences that can lead to implicatures or the implicatures themselves. In this way, we can see how analysts have often underplayed the contingency of inferences as well as the inherent indeterminacy of implicatures in such debates. It is proposed that cancellability should thus be the subject of further empirically-driven analyses in order to provide a solid foundation for the theorization of implicature.
\end{abstract}

\section{Introduction}

In introducing the theory of conversational implicature, Grice made three key claims, each of which has subsequently become the subject of considerable debate in pragmatics. First, Grice claimed that the inferences underlying conversational implicatures are made in a principled way. In other words, conversational implicatures are made available to recipients by speakers with reference to normative assumptions about the nature of cooperative interaction (cf. Bianchi this volume). Grice formalised this claim in postulating the Cooperative Principle and four related conversational maxims. Second, conversational implicatures are generated through ordinary reasoning (as opposed to strict logical reasoning), either once-off reasoning in a particular context (nonce inferencing), or regularised or conventionalised reasoning across contexts (default inferencing). Third, since conversational implicatures arise through ordinary as opposed to strictly logical reasoning, 
these inferences are defeasible, from which it follows that a putative implicature can always be cancelled. Grice argued that a conversational implicature can be cancelled in two different ways. Explicit cancellation involves adding a subsequent cancellation clause that either retracts the implicature (e.g., "not that I mean [to imply $x$ ]") or blocks it from arising in the first place (e.g., "in fact [not $x$ ]". Contextual cancellation involves finding situations in which the putative implicature would not arise (Grice 1989: 44).

The standard position in pragmatics to date has thus been that implicatures are cancellable through explicit and/or contextual cancellation, and that the "cancellability test" is useful way of differentiating implicatures from logical implications, semantic entailments and the like (see, e.g., Blome-Tillmann 2008: 156). Cancellability, in other words, has often been assumed to be one of the necessary, albeit not sufficient, tests for identifying implicatures. In recent years, however, there has been considerable debate as to whether implicatures are always in fact cancellable, or indeed whether they are cancellable at all amongst linguistic pragmaticians and language philosophers. ${ }^{1}$ Much of this debate has arisen as a consequence of the conflation of the different orders of language description that these two types of cancellation represent, as Jaszczolt (2009) has pointed out. Explicit cancellation is of primary importance to those analysing implicatures in actual discourse, for instance, while contextual cancellation is more pertinent to those engaging in analyses of individual utterances. In this chapter, I attempt to further reframe the terms of this debate by proposing that "cancellability" plays out in different ways depending on whether we are analysing inferences that can lead to implicatures or the implicatures themselves. An implicature is a type of speaker meaning that goes beyond what is literally said. More specifically, implicatures pertain to separate individual, additional thoughts with their own pragmatic force (Haugh 2002: 128-130, Haugh and Jaszczolt 2012: 96). Inference, in contrast, refers to the cognitive processes by which participants figure out (speaker) meaning beyond what is said or encoded. While many scholars treat implicatures as essentially synonymous with non-logical/pragmatic inference (Carston 2002, Levinson 1983, 2000, Sperber and Wilson 1995), other scholars insist that assimilating implicature to inference constitutes a conceptual and analytical error (Bach, 2006, Horn 2004, 2012). In this chapter I favour the latter position. A key difference between the two is arguably that while speakers can be held accountable for (or committed to) implicatures to varying degrees, neither speakers nor recipients are held accountable for all the inferences they make when participating in interaction (unless they make available such inferences to others through saying or implying). It is thus argued here that a clear distinction between inference and implicature

\footnotetext{
${ }^{1}$ It is worth noting that this debate has also been extended to the relevance theoretic concept of explicature (see Burton-Roberts 2010, Capone 2006, 2009, 2010, and Carston 2002, 2010 for further discussion). However, those debates are only touched upon here to the extent they make reference to the (neo-)Gricean notions of particularised and generalised conversational implicatures.
} 
needs to be maintained if we are to succeed in unravelling some of the recent controversy over the cancellability (or not) of implicature.

I start this chapter by outlining three of the key challenges to the validity of cancellability test for implicatures that have been raised thus far. The first of these is claim that implicatures may in some instances be entailed and thus cannot strictly speaking be cancelled since such cases involve logical inferences that are not defeasible. The second is the argument that something which is speaker intended, such as a particularised conversational implicature cannot be "un-intended", and thus such implicatures cannot, by definition, be cancelled. The third involves cases of so-called cancellation-resistant implicatures, where explicit cancellation phrases are either non sequitur or end up reinforcing the implicature. In the course of discussing these various challenges I suggest that analysts have tended to underestimate the contingency of implicatures and over-estimate their degree of determinacy. Building on this discussion, I next focus on cancellability vis-à-vis inference, suggesting that blocking and suspension are two of the key ways in which inferences might be "cancelled". I also argue that the blocking or suspension of pragmatic inferences is more productively conceptualised as a consequence of their inherent contingency rather than defeasibility, in contrast to what is traditionally assumed in theorising implicature. I then discuss cancellability vis-à-vis implicature, and propose that we are dealing here with two quite different social actions that can arise as a consequence of the use of cancellation phrases in interaction, namely, correction/repair and reinforcement. The former type of action encompasses denying, retracting or clarifying what has been implied, and is arguably a function of the degree of indeterminacy of the implicature in question, as well as the extent to which a speaker can be held to be implying something. Whether an implicature can be plausibly or legimately denied, retracted or clarified by the speaker is thus proposed to be an empirical question, which requires recourse to an account of the ways that speakers make implicatures available to recipients through appeals to normative frames of interpretation, as well as issues of salience and sequential placement. The latter type of action, namely, reinforcement arises as a function of the way in which implicatures can be strengthened or bolstered without redundancy through cancellation phrases. I conclude by suggesting that rather than being abandoned, as suggested by Carston (2002, 2010), cancellability ought to be the subject of further analyses that acknowledge the critical distinction between forms of "cancellation" that apply to inference as opposed to implicature.

\section{The cancellability debate in pragmatics}

A number of apparent challenges to the cancellability of implicatures have been raised in recent years. In this section, I briefly discuss each of these challenges in turn. 


\subsection{Implicature and entailment}

One challenge to the efficacy of the cancellability test has been the observation that in some cases, implicatures can also be treated as entailments (Bach 2006: 24, Carston 2002: 138-140, Higashimori and Wilson 1996: 122, Vicenti 1998; cf. Wilson and Sperber 1986: 61). Entailment is a type of semantic relation between propositions ( $p$ and $q$ ) where $p$ entails $q(p \| q)$ if and only if the truth of $p$ guarantees the truth of $q$ (Huang 2007: 16, Levinson 1983: 174). An implicature, in contrast, is generally assumed to rely on a pragmatic relation, $p$ implies $q(p+>q)$, which is non-truth conditional (i.e., the truth of $q$ is independent of $p$ ). However, if an implicature is also entailed then it would appear the implicature cannot strictly speaking be cancelled, because the truth of the implicature is no longer independent of the truth of what is said in such cases. A number of examples have been proposed that illustrate instances where what is implied (by the speaker) is also entailed (by the utterance).

(1) Peter: Would you like to listen to my Rolling Stones record?

Mary: No. I'd rather hear some music.

$+>$ Peter's Rolling Stones record is not music.

|f Peter's Rolling Stones record is not music.

(Higashimori and Wilson 1996: 122)

(2) Adam: Does John drink slivovitz?

Bob: He doesn't drink any alcohol.

$+>$ John does not drink slivovitz.

\|- John does not drink slivovitz.

(Carston 2002: 139; cf. Wilson and Sperber 1986: 61)

(3) Andy: Nobody has ever long-jumped over 28 feet.

Bill: Whad'ya mean? Bob Beamon long-jumped over 29 feet way back

in 1968.

+> Somebody has long-jumped over 28 feet.

|- Somebody has long-jumped over 28 feet.

(Bach 2006: 24)

In the above examples, what is implied by the speaker also logically follows from what is said by analytic rule. In other words, we have instances of implicated entailments. Carston (2002) argues that such examples demonstrate that "noncontradictory cancellability is not a necessary property of implicatures” (p.140). However, as she latter admits, "the concept of entailment and the concept of implicature belong to different explanatory levels, in fact different sorts of theory the one a static semantic theory which captures knowledge of linguistic meaning, the other an account of the cognitive processes and representations involved in understanding utterances” (Carston 2004: 644). Building on this point, I would suggest that there are two important differences between analyses of entailment and implicature that bear on the issue of cancellability.

First, implicatures are not required to be formally determinate in the same way as entailments. Higashimori and Wilson's (1996) gloss of example (1), for in- 
stance, brushes over all sorts of possible indeterminacy in the interpretation of Mary's response. For a start, while they claim that Mary implies the Rolling Stones is "not music", clearly we're dealing with something more than that. Mary's response could be interpreted as her implying it is "not real music", "not good music", "not pleasant to listen to music" and so on and so forth. It also remains indeterminate as to who this evaluation is attributed to. Is it just Mary who thinks this, or is she implying that "others" (e.g. people of good taste) might also share the same belief? Such issues of indeterminacy in interpretation lie outside the scope of formal analyses of entailments, but they are critical for the interpretation of implicatures. For this reason they bear on issues of cancellability, as such nuances in interpretation allow for the speaker (in this case Mary) to subsequently deny particular interpretations on the part of the recipient (Peter) on the basis that she didn't say that which has been specifically attributed to her. As Bach (2006) points out, "it's not what the speaker says but that he [or she] says it (or even that he [or she] puts it a certain way) which carries the implicature" (p.24). In that sense, this is what gives Mary an edge over Peter in determining what has been implied. Peter may, of course, have his doubts, and so this denial might be disputed, but the very fact that what has been implied can be disputed means there is more to the cancellability issue than first meets the eye.

Second, the interpretation of implicatures is inevitably contingent on context, including what comes before and after the utterance in question, as well as the presuppositions of speakers (and recipients). Entailments, on the other hand, involve a strictly defined and fixed set of assumptions. In example (2), for instance, Bob could subsequently add something like "except for the odd tot of slivovitz" without contradiction of what is said, thereby "removing" the entailment relation between his utterance and what would have been implied without this proviso (i.e. "John does not drink slivovitz"). In that case, what is implied is something along the lines that John's habit of drinking slivovitz (albeit not often) is quite striking in light of his general abstinence from drinking alcohol.

Bach's (2006) example of an implicated entailment seems more difficult to remove, in part because it arises not only through Bill's assertion, but Bill's assertion in response to Andy's assertion. However, once again the interpretation of this putative implicature can be shown to be contingent on subsequent discourse. Bill might add something like "although if you mean since Beamon's jump then you're right" if he believes (falsely) that no one has jumped over 28 feet since Beamon's 29 feet jump in 1968, and moreover attributes this (false) belief to Andy. All in all, this suggests that the application of formal types of analyses to natural language usage is somewhat fraught, as ordinary discourse involves all sorts of contingencies that are not accounted for within strictly formalistic approaches, including the analysis of entailment relations. ${ }^{2}$

\footnotetext{
${ }^{2}$ The same limitations also face appeals to strict logic-based analyses that are implicit to the notion of defeasibility as will be discussed further in Section 3.
} 


\subsection{Implicature and speaker intentions}

A second challenge to the claim that implicatures are cancellable is more rhetorical in nature. Based on the general assumption that implicatures are speakerintended, a number of scholars have argued that once something is intended it cannot be "unintended", and thus particularised conversational implicatures, at least, are not cancellable by definition (Burton-Roberts 2006, 2010; Capone 2009, 2010). Burton-Roberts (2010), for instance, argues that "There is no question, with PCI [particularised conversational implicature], of the implicature in any sense 'arising' independently of the speaker's intention. In short, a PCI is only ever an actual implicature. My claim, then, that PCIs (as actual) must be interpreted as intended and so cannot be cancelled" (p.151, original emphasis). Capone (2006, 2009, 2010) is more circumspect in allowing for cases of weak commitment or vagueness in some examples of implicatures. He nevertheless argues that in instances where there is "strong intentionality", the resulting implicatures are not cancellable:

When a strong intentionality is projected, it can no longer be retracted. Implicature can only arise if intended and recognized as intended, but then it should be impossible to cancel an implicature: how would it be possible to withdraw/cancel what was intended to be implicated and was recognized as intended? An implicature could only be

withdrawn/cancelled if it were not intended. But then it shouldn't be an implicature (since implicatures by definition are intended); in other words there would be no implicature to cancel. (Capone 2010: 502; cf. Capone 2009: 59)

One problem with this line of argument, however, is that it is somewhat circular. It is assumed that implicatures are intended "by definition", with this conceptualisation of "implicature as intended" being subsequently used to undermine the idea that implicatures can be cancelled. However, while some argue that Grice regarded conversational implicatures as speaker-intended (cf. Bianchi this volume; Davis 1998), there are good reasons to believe the relationship between speaker (intended) meaning and implicature is not quite as straightforward as might first appear. Grice himself originally made a distinction between 'implicature' and 'implicatum'. The former referred to the process of meaning (in the sense of intending) something in addition to what is said, and was thus restricted to the speaker. The latter referred to the product of that process, which could arise from inferences by either the speaker or the recipient (Haugh and Jaszczolt 2012). The term 'implicature' gradually came to refer to both notions, however, thereby obscuring the important distinction between speaker-implicatum and recipientimplicatum (cf. ‘utterer-implicature' and 'audience-implicature') (Saul 2002; Horn 2012). Retaining such a distinction means recognising not only that speakers may be taken to be implying something that is contrary to their claimed intention (Cummings 2005: 20-21; Haugh 2008a, 2008b; cf. Bach 2001, 2006; Capone 2010: 502, fn.3), but also that speakers (and writers) can intentionally leave the interpretation of what has been implied open to the recipient (Jaszczolt 1999: 85; Haugh 2011). If we can admit that "the subsumption of conversational implicature 
within the category of speaker meaning is not entirely straightforward" (Horn 2012), then it becomes an empirical question as to whether an implicature is "cancellable" without contradiction. After all, are we trying to analyse only what a particular theory recognizes as a legitimate object of study or what is empirically recognizable (to participants) in the world? If we assume the latter position, the above argument is open to empirical question.

It is also worth noting that implicatures are not always as determinate as is often assumed by analysts. A number of classic examples of implicature originally noted by Grice turn out to be more indeterminate than those taking the stance that implicatures are speaker intended (and thus by definition not cancellable) allow for. Capone's (2009) discussion of Grice's classic example of an implicature arising through a testimonial for a candidate applying for a philosophy job is somewhat illuminating in that respect. ${ }^{3}$ The example as given by Grice is reproduced below.

(4) Dear Sir, Mr. X's command of English is excellent, and his attendance at tutorials has been regular. Yours, etc. (Grice 1989: 33)

While Grice argued that what was implicated here was that A thinks "Mr. X is no good at philosophy" (Grice 1989: 33), Capone's discussion indicates that there are at least two possible implicatures here: first, the writer does not support the candidate's application for the job, and second, the write thinks the candidate is not a good (or a poor) philosopher. These two implicatures are both indeterminate. As Capone (2009) points out, "though A could deny not having supported his student, he certainly could not assert his support" (p.57). In other words, the first implicature is indeterminate as to whether the writer is strongly against the candidate's application or just indifferent, although normatively we might assume the former interpretation. The second implicature is also more indeterminate than often recognised. To be labelled as "not a good philosopher" is not the same thing as being labelled "a poor philosopher". There is a difference of degree here. In implying a broadly negative (or at least not positive) evaluation, the writer is exploiting this indeterminacy. The writer could argue, for instance, that he is not implying that Mr. X is a poor philosopher, but simply not saying he is a good philosopher. There are limits to the plausible deniability of implicatures, of course. However, this is not so much a function of what is written down by the writer, as a function of the activity type of writing testimonials, where readers have legitimate expectations constraining what can be meant by such a letter. It could be argued, then, that while in normal circumstances (i.e., when writing testimonials) the writer may be taken as making available, by conversational implicature, something to the effect that the candidate is not a good philosopher, and furthermore that he does not support the candidate's application, these conversational implicatures are

\footnotetext{
${ }^{3}$ Another point worth noting in passing is that in discussing this example in regards to its cancellability, Capone (2009) makes reference to the notions of "retract", "revise", "deny", "disintegrate" and "unimplicate", although these are clearly not equivalents. This suggests that "cancellability” encompasses different kinds of processes and actions, as discussed further in Sections 3 and 4.
} 
not necessarily synonymous with what the writer thought he had implied (speakerimplicatum) or how the reader interpreted this letter (recipient-implicatum), due to their inherent indeterminacy.

Burton-Roberts (2010) offers another example of an implicature that is allegedly not cancellable.

(5) Max: Do you ever speak to Charles?

Ann: I never speak to plagiarists.

$+>$ Charles is a plagiarist

(Burton-Roberts 2010: 151)

The first thing to note here is that once again there are at least two implicatures that potentially arise here. The first is an implicated presumption (i.e. Charles is a plagiarist), while the latter is an implicated conclusion (i.e. I don't speak to Charles). The latter putative implicature can be straightforwardly cancelled with an "except for" clause. The former potential implicature appears more resistant to cancellation, but this is only if it is assumed that the implicated presumption is determinate. On closer examination, however, it appears that there is in fact real indeterminacy in regards to the speaker's degree of certainty about this suggestion. The speaker is not strictly speaking committed to the claim that Charles is definitely (cf. "is") a plagiarist, although Max might have (normatively) taken her to be so committed. Thus, the implicature can indeed be removed by Ann simply adding something like "And I think Charles might be one”, thereby indicating her uncertainty about such a claim. Or she might, in a more convoluted manner, subsequently claim that "I am not saying that Charles is a plagiarist for sure, mind you, just that I think he probably is one”. Max could, of course, dispute this claim. But therein lies the point: implicatures are not determinate, which is why they can be disputed in the first place.

Following Grice's (1975: 58) characterisation of implicatures as indeterminate, Sperber and Wilson (1995) argue that:

there has been a tendency in modern pragmatics to treat all implicatures along these lines: as fully determinate assumptions for which the speaker is just as much responsible as if she had asserted them directly. On this approach, utterance comprehension consists in the recovery of an enumerable set of assumptions, some explicitly expressed, others implicitly conveyed, but all individually intended by the speaker. (p.195)

Although the degree of indeterminacy of implicatures is likely to be gradable along some kind of scale (from strongly through to weakly indeterminate) ${ }^{4}$ they are nevertheless always indeterminate in some respects simply because they are not said. Claiming that implicatures inevitably indeterminate is a distinct issue from the question of whether something has been implied or not. In some instances, participants would argue that clearly something has been implied, and in such cases it is not plausible for the speaker to deny having meant something in addi-

\footnotetext{
${ }^{4}$ Cf. Sperber and Wilson (1995) who claim that implicatures vary in their degree of determinacy, that is, from strongly determinate (strong implicatures) through to weakly determinate (weak implicatures).
} 
tion to what is said. But due to the inherent indeterminacy of implicatures this something is never entirely fixed. Ultimately, then, it makes little difference whether or not one subscribes to a definition of implicatures as only encompassing those that are speaker-meant (or intended), as it is through appeals to "normal circumstances" that we take something, which is more or less indeterminate, to be implicated, as Grice originally argued (Wilson and Sperber 1986: 71). On this view, their degree of "cancellability" thus remains an empirical question.

\subsection{Cancellation-resistant implicatures}

While it has been suggested thus far that arguments against the efficacy of the cancellability test are not as straightforward as what might first appear, there are nevertheless instances where the implicatures appear to simply defy explicit cancellation.

Sarcasm or irony has been analysed as arising through implicature, following Grice's (1989: 34, 53-54) discussion of irony. Grice claimed with reference to the following example, for instance, that a conversational implicature can be generated through flouting the first maxim of Quality.

(6) (X, with whom A has been on close terms until now, has betrayed a secret of A's to a business rival. A and his audience both know this)

A: $\mathrm{X}$ is a fine friend. (Grice 1989: 34)

Grice suggests that what is implicated here is a proposition "contradictory of the one he purports to be putting forward" (Grice 1989: 34) (i.e., $X$ is not a fine friend). Grice (1989) also notes that irony involves "the expression of a feeling, attitude or evaluation" (p.53), the exact content of which is generally fairly indeterminate, although it can be understood as broadly "negative" in the case of sarcasm.

However, it has been pointed out that irony generated through implicature resists explicit cancellation (Huitink and Spenader 2004; Weiner 2006). While Jaszczolt (2009) points out that this does not mean that such instances "fail" the cancellability test per se, since contextual cancellation is always another possibility, the existence of implicatures that are resistant to explicit cancellation does nevertheless throw up interesting questions for analysts. In the examples given by both Huitink and Spenader (2004) and Weiner (2006), an attempt to cancel the irony ends up simply reinforcing it, because the cancellation phrase itself is interpreted ironically. In the following example, for instance, we can see how the cancellation phrase does not necessarily retract, deny or clarify what is implicated here, but rather can reinforce the ironic stance of the speaker.

(7) Mr. X's command of English is excellent and his attendance at tutorials has been regular. He is a brilliant philosopher. (Huitink and Spenader 2004: 8; cf Grice 1989: 33) 
They suggest here this is because "the cancelation phrase itself is interpreted non-literally...as such, the second sentence confirms the implicature of the first sentence" (Huitink and Spenader 2004: 8). It appears that the likelihood of a cancellation phrase being interpreted ironically is a function of the way in which the prior implicature arose (i.e. whether in an ironic or non-ironic interpretative frame), and the degree of salience of an ironic interpretation relative to the topic and activity type in question (cf. Huitink and Spenader 2004: 10).

Another type of cancellation-resistant implicature arises in instances where utterance-final connectives reinforce the inference leading to implicature such that it becomes difficult, if not impossible, to plausibly retract or deny it. In the following excerpt from a telephone conversation there is an implied refusal that is reinforced through the deployment of an utterance-final kara ('so').

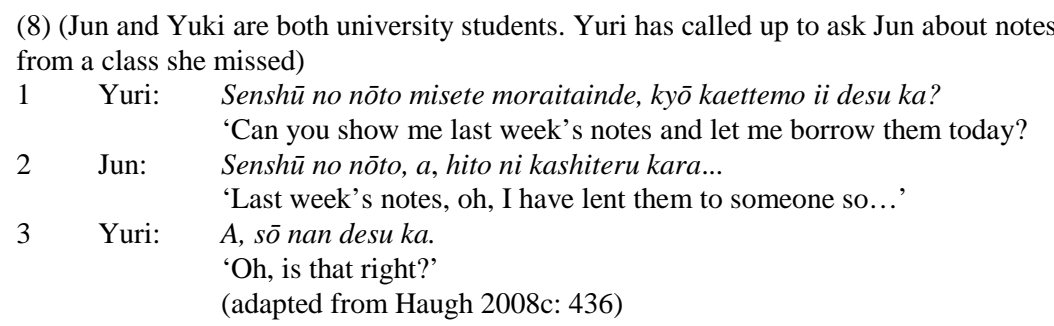

Yuri first asks Jun whether she can borrow some notes from the previous week's class (turn 1). Jun responds by saying he has already lent the notes to someone else. The utterance-final kara ('so') in turn 2 is exploited by Jun to indicate this is a reason for what is implied here, namely, that he is not able to give the notes to Yuri today. Yuri claims understanding of this implied refusal in her response in turn 3. We can thus see here that utterance-final conjunctives can be exploited to reinforce implicatures in light of the fact that conjunctive kara ('so', 'because') is canonically attached in Japanese to subordinate clauses to indicate a cause or reason for an action or attitude that is described in the main clause. Through the deployment of such conjunctives the speaker also retains greater control over the subsequent inferences made by the recipient, which means such implicatures are not explicitly deniable. The speaker could have subsequently claimed that he was thinking of notes for another class, and that in fact he does have the notes $\mathrm{A}$ is asking for, thereby correcting or repairing the prior implicature that he cannot lend the notes to B. However, this is not because the implicature is "cancellable", as it still holds from what was previously said by Jun. It is simply that the speaker has indicated he is no longer committed to what has been implied. In this case, the inference leading to the implicature is not so much defeasible as contingent on prior and prospective utterances (cf. Haugh 2008c: 445-446).

In the course of this discussion, I have alluded to the claim that much of the current debate about the cancellability test has unnecessarily conflated implicatures with both speaker (intended) meaning and inference. It has been suggested that implicatures are not as determinate, while inferences are more contingent, than is often assumed by analysts. There are, nevertheless, instances where impli- 
catures do indeed appear to defy straightforward "cancellation". In the following two sections, I go on to suggest that such issues may be more productively examined by carefully distinguishing between cancellation vis-à-vis inference as opposed to implicature

\section{3 “Cancellability” vis-à-vis inference}

Inference is a form of reasoning whereby we can either draw consequences that a proposition has by virtue of truth-conditions (leading to entailments), or those which seem necessary, permissible or reasonable for one to draw (leading to implicatures, among other things) (Woods 2010: 218). The former type encompasses logical inferences that are not strictly open to error. The latter type encompasses inferences that are generally characterised as defeasible, which means they always allow for the possibility of error. In other words, they may not seem necessary, permissible or reasonable in certain situations. It is commonly assumed the different kinds of pragmatic inference leading to implicatures are cancellable because of their inherent defeasibility (Levinson 1983, 2000), but strictly speaking only nonmonotonic inferences can only be "cancelled" in the sense of either being blocked or suspended. ${ }^{5}$ In this section, I suggest that on closer analysis, "cancellablity" appears to involve two different processes in relation to inferences, namely, blocking and suspension.

Blocking inferences encompasses instances where a potential inference, which could conceivably follow from something that has been said, is not allowed through by the speaker. Blocking is thus prospective or anticipatory in nature. It generally occurs in cases where there is an unwanted inference, that is, something that could be inferred from what is said, but which the speaker does not wish to commit to, or be held accountable for, meaning. Blocking inferences thus contrasts with "contextual cancellation" or "non-arising" where "meanings are neither intended nor inferred: they are just 'conceivable' in a thought experiment" (Jaszczolt 2009: 261). A speaker can block unwanted inferences that the recipient might be expected to otherwise draw through various connectives that implicitly orient to what could have been inferred, including "but $x$ ” (examples 9 and 10), "if not $x$ ” (example 11), "in fact/actually $x$ " (example 12) and so on.

(9) A: Will Sally attend the meeting?

B: Her car broke down, but she'll still be there. (Huitink and Spenader 2004: 9)

(10) A: Smith doesn't seem to have a girlfriend these days.

\footnotetext{
${ }^{5}$ We can further distinguish between defeasible inferences that are monotonic and those that are non-monotonic. Monotonicity refers to the property of inferences whereby the addition of new information does not reduce the set of what is known, and so no matter what further premises are added to a given premise set (provided none of the existing ones are erased), the set of conclusions can only increase. Non-monotonicity, on the other hand, refers to inferences where their present reasonability may be lost upon the addition of new information.
} 
B: He has been paying a lot of visits to New York lately, but I don't think he has a girlfriend there. (Huitink and Spenader 2004: 10; cf. Grice 1989: 32)

(11) Some, if not all, the people left the building.

(12) Some, in fact all, the people said they liked the food. (Jaszczolt 2009: 261)

In example (9), we can see how the second phrase blocks the (unwanted) inference that Sally will (probably) not attend the meeting. In example (10), in contrast, we can how the second phrase blocks the (unwanted) inference that Smith has a girlfriend in New York, although it does not block the inference that Smith might have a girlfriend there but rather reinforces it. In example (11), the inference that not all of the people left the building is blocked by the intervening "if not" phrase, whereby the speaker implies epistemic uncertainty instead; that is, he or she is not sure whether or not everyone has left the building. ${ }^{6}$ This contrasts with example (12), where the inference that not all the people said they liked the food is blocked by the intervening "in fact" phrase. In each instance, the connective itself orients to a possible inference that is subsequently blocked by indexing a contrast with what could have been inferred.

Suspension, on the other hand, involves removing the speaker's commitment to an inference that has already likely been drawn, and is thus retroactive in orientation. In the following excerpt from a recording of a telephone conversation between friends, for instance, we can observe how the potential default inference is suspended by a subsequent nonce inference.

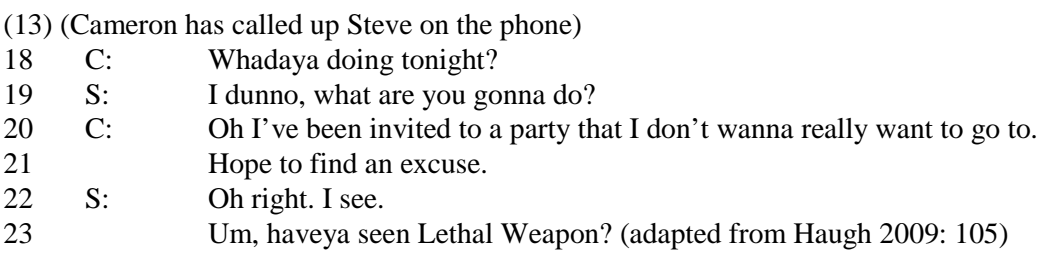

In this short interchange, Cameron's initial question in line 18 is in the form of a standard pre-invitation (Schegloff 2007: 129). In other words, in a minimal context, namely, two friends talking on the phone, the speaker standardly implies through this utterance-type that he is going to subsequently invite the recipient to do something together, if the preparatory condition that has been invoked is met (i.e. that the other person is available). Steve orients to this possible invitation (and thus a putative short-circuited implicature) by inquiring about what the invitation might involve (line 19). This default inference, however, is subsequently suspended in Cameron's next turn where he outlines the preparatory conditions for another kind of invitation, namely, an invitation from Steve (lines 20-21), thereby implying that he would like Steve to invite him somewhere (and so provide the means by which he can be excused from going to a party he doesn't want to attend). This

\footnotetext{
${ }^{6}$ Cf. Levinson (1983: 115, fn.15) who analyses this as an instance where the speaker is not committed to the truth or falsity of the implicature (so-called "suspension" of implicature).
} 
latter implicature, through which Cameron solicits an invitation from Steve, arises from a nonce inference drawing from specific contextual information. The change in Steve's understanding of the upshot of Cameron's prior utterance in line 18 in light of this qualification (in lines 20-21) is evident from his use of 'oh' and 'right' (line 22), through which he receipts 'new' information and understanding respectively (Heritage 1984; Schegloff 2007: 118), and his subsequent issuing of an invitation sequence (data not shown) starting with a standard pre-invitation (line 23) (cf. Haugh 2009: 104-107). In this example, then, we can see how the response of the recipient (Steve) helps constrain what is inferred amongst the potential interpretations initially afforded by the speaker's (Cameron) first utterance, an understanding which is subsequently qualified by the first speaker (Cameron). It is the contingency of this inferential work that allows for the suspension of the default inference that was initially drawn by the recipient (Steve).

The current analysis can also be taken to suggest that the blocking or suspension of pragmatic inferences could be more productively conceptualised as a consequence of their inherent contingency rather than defeasibility. One reason for this is that defeasibility presumes a "logical" basis for analysing inference that arguably carries with it unnecessary baggage for the analysis of natural language use. While some pragmatic inferences may seem akin to logical inferences, the interpretation of natural language use is not bound by the formal restrictions of logical analysis. Thus, invoking (pseudo-)logical constraints on the analysis of the inferential work underlying the interpretation of implicatures is misleading as it involves a different order of analysis and language description. A second reason for favouring contingency over defeasibility is the observation that entailments can be implicated. In such cases, the inference leading to the implicated entailment cannot be cannot be regarded as defeasible (i.e. open to error), because inferences underpinning entailments are logical (i.e. follow analytic rules), and thus are not open to error strictly speaking. They are nevertheless contingent on what precedes and follows the utterance in question, as the implicated entailment can be "removed" through an "except for" clause, for instance, as was discussed in Section 2.1. The non-defeasibility of some instances of pragmatic inference also became apparent in the course of the discussion of various instances of cancellationresistant implicatures (Section 2.3). Thus, while we may admit that implicatures are always contingent, this is not because the underlying inferences are necessarily always defeasible, but rather because pragmatic inferences are always anticipatory and retroactive in nature (Haugh 2012: 263).

\section{4 “Cancellability” vis-à-vis implicature}

An implicature is commonly conceptualized as a species of speaker meaning that pertains to separate individual, additional thoughts with their own pragmatic force, as previously noted. It was also pointed out that different types of implicatures can be distinguished on the basis of the distinction between conventionalized 
reasoning across contexts (default inference), and once-off reasoning in particular contexts (nonce inference). The former generate default implicatures, while the latter generate nonce (or particularised) implicatures, with a further distinction possible between default implicatures that arise across all contexts unless otherwise cancelled (generalised implicatures), and those that only require a minimal context in which to arise (short-circuited implicatures). Finally, it has also been noted that we can draw a distinction between speaker-implicatum and recipientimplicatum (or 'utterer-implicature' and 'audience-implicature'). ${ }^{7}$ Since implicatures are "products" of inferring, then, they can vary both in terms of who is doing the inferring (i.e. speaker or recipient), and in relation to what kind of inference is involved (default or nonce). Moreover, since they are also "products" of implying they are recognisably social or normative in nature. An upshot of taking this position is that the cancellation of implicatures is conceptualised a kind of speech act or social action in itself (Borge 2009: 152). And furthermore, in constituting a social action, cancellation may be therefore be taken literally or non-literally (Jaszczolt 2009: 264). In examining instances of the "cancellation" of implicatures in discourse it appears there are two broad categories of social action involving explicit cancellation.

The first is correction or repair. An explicit cancellation activates a kind of "not-frame" which presupposes there is something there to cancel in the first place. In this sense, then, we cannot talk of an implicature being removed or no longer existing. And for this reason a distinction between "cancellation" and "correction" of implicatures is difficult to maintain (cf. Bultinck 2005: 35; Jaszczolt 2009: 266-267). Instead, we can talk of implicatures being open to denial (e.g. claims that the implicature was not speaker intended), retraction (e.g. claims that the implicature is no longer relevant or applicable to the current discourse), or clarification (e.g. claims that what was meant is different to how it was understood or might have been understand by the recipient), among other things. All of these actions involve modulation, in some form or another, of the degree of the speaker's commitment to, or accountability for, the implicature in question. The plausibility or legitimacy of the actions of denial, retraction or clarification is a function of the degree of indeterminacy of the implicature in question as well as its status vis-à-vis primary and secondary meanings. This means that "cancellability" is a gradable property, dependent, in part, on the speaker's perceived intentions (Haugh and Jaszczolt 2012: 96). Perceived intentions are, in turn, a function of the degree of salience of the implicature in question, as well as the sequential placement of the utterance that gives rise to it (i.e. whether it is closely linked to a prior utterance and thus dependent on how the prior speaker's utterance is understood). In other words, the degree of plausibility of denying, retracting or clarifying an implicature is a function of what is normatively made available by the speaker in

\footnotetext{
${ }^{7}$ We might add a third category, namely, “emergent implicature” (cf. Haugh 2008a, 2009), where implicatures are interactionally achieved across speaker-recipient dyads, but further consideration of this must await another time, as whether one accepts the validity of such a notion does not substantively impact on the points being made here.
} 
saying $x$. In cases where something has clearly been implied (i.e. implicature as primary meaning), the speaker can usually only clarify what was implied. In cases where it is open to interpretation whether something has been implied (i.e. implicature as secondary meaning), then implicatures may be more readily denied or retracted as well. In all cases, however, correction/repair actions are always open to dispute by participants as to what exactly was implied, or the degree of speaker commitment to what was taken to be implied, given the existence of both speaker and recipient implicatum.

In the example below taken from an episode in Seinfeld, for instance, the two characters argue about whether something has been implied by Elaine's question. The conversation begins when Elaine reports that her colleague, who is a former alcoholic, mistakenly took Jerry's drink at a party they had all attended, and has since started drinking again, leading to his dismissal.

(14) (“The red dot”, Seinfeld, Season 3)

Elaine: Dick was fired.

Jerry: You mean to tell me if I had put that drink six inches over to the right, and none of this would have happened.

Elaine: You knew he was an alcoholic. Why'd you put the drink down at all?

Jerry: What are you saying?

Elaine: I'm not saying anything.

Jerry: You're saying something.

Elaine: What could I be saying?

Jerry: Well you're not saying nothing you must be saying something.

Elaine: If I was saying something I would have said it.

Jerry: Well why don't you say it?

Elaine: I said it.

Jerry: What did you say?

Elaine: Nothing. (sighs) It's exhausting being with you.

Here Jerry and Elaine use saying not so much in the sense of uttering but rather in the sense of meaning something, more specifically, something that is not said but implied. We have here, then, an example of an attempted denial of an implicature, although what exactly is being denied is never made clear. Notably, while Jerry appears to appeal to what would be normatively interpreted as being made available via implicature by Elaine's question ("Well you're not saying nothing you must be saying something”), Elaine invokes her own intention to deny implying anything ("If I was saying something I would have said it"). ${ }^{8}$ Disputes about attempts by speakers to deny, retract or clarify implicatures can be, of course, much more consequential or serious than in this example, as discussed with reference to media disputes about what was implied by a prominent religious figure in Australia (Haugh 2008b).

The second broad category of social action involving explicit cancellation phrases has already been alluded to, namely, reinforcement, where the implicature is reiterated without redundancy. Weiner's (2006) example of a cancellation-

${ }^{8}$ Cf. Capone (2009) on social versus individual intentionality. 
resistant implicature illustrates rather nicely how what can appear on the surface to be an attempted cancellation, is in fact reinforcing the sarcasm.

(15) (Alice and Sarah are in a crowded train. Alice, who is obviously able-bodied, is sprawled across two seats, and Sarah is standing)

Sarah: I'm curious as to whether it would be physically possible for you to make room for someone else to sit down. Not that you should make room; I'm just curious.

(Weiner 2006: 128)

Here we can see how the second utterance, which is formulated as a denial that she is implying she wants Alice to move, does not involve correction or repair but rather reinforcement of a sarcastic stance on the part of Sarah. It is also worth noting that while it is obvious that the speaker is not committed to what is said here (i.e. Sarah is clearly not curious), the implied feeling, attitude or evaluation is quite indeterminate, albeit obviously negative. However, in constituting a highly salient, primary meaning, this latter implicature cannot be readily retracted or denied, although it is nevertheless open to clarification.

\section{Concluding remarks}

These debates have highlighted a number of apparent contradictions for both (neo-)Gricean and relevance theoretic approaches to implicature: not all implicatures are necessarily speaker intended, and inferences should not be treated as synonymous with implicatures. It has been suggested here that current debates about cancellability may be advanced by acknowledging such distinctions. It has also been argued that any analysis of cancellability vis-à-vis inference and implicature should recognise both the inherent contingency of inferences, and the inherent indeterminacy of implicatures. The question of whether inferences or implicatures are "cancellable" is thus an empirical question. This is not to deny the utility of debates around cancellability that test the internal coherence of particular theoretical stances, but rather to suggest that a more nuanced understanding of "cancellability" can help us to better understand the underlying nature of implicatures.

It has also become apparent in the course of this discussion that cancellability does not provide a reliable means of distinguishing between semantic and pragmatic contributions to meaning, as has already been noted (Cartson 2010; Jaszczolt 2009). The theoretical relevance of cancellability itself for pragmatics has thus come into question. This has led researchers to two quite different conclusions. On the one hand, Carston (2010) has suggested that it simply be abandoned. On the other hand, Jaszczolt (2009) has suggested that it needs to be the subject of further empirically-driven analyses. In this chapter, I have taken the latter route. I have suggested that a careful examination of how cancellability plays out in the case of different examples of inferences and implicatures remains useful 
in advancing our understanding of meaning beyond what is said, and the inferences that give rise to it.

\section{References}

Bach, Kent. 2001. You don't say? Synthese 128:15-44.

Bach, Kent. 2006. The top 10 misconceptions about implicature. In Drawing the Boundaries of Meaning. Neo-Gricean studies in pragmatics and semantics in honor of Laurence R. Horn, eds. Betty Birner and Gregory Ward, 21-30. Amsterdam: John Benjamins.

Blome-Tillmann, Michael. 2008. Conversational implicature and the cancellability test. Analysis 68:156-160.

Borge, Steffen. 2009. Conversational implicatures and cancellability. Acta Analytica 24:144-154.

Bultinck, Bert. 2005. Numerous Meanings: the Meaning of English Cardinals and the Legacy of Paul Grice. Oxford: Elsevier Science.

Burton-Roberts, Noel. 2006. Cancellation and intention. Newcastle Working Papers in Linguistics 12/13:1-12.

Burton-Roberts, Noel. 2010. Cancellation and intention. In Explicit Communication. Robyn Carston's Pragmatics, eds. Belén Soria and Esther Romero, 138-155. London: Palgrave Macmillan.

Capone, Alessandro. 2006. On Grice's circle (a theory-internal problem in linguistic theories of the Gricean type). Journal of Pragmatics 38:645-669.

Capone, Alessandro. 2009. Are explicatures cancellable? Towards a theory of the speaker's intentionality. Intercultural Pragmatics 6:55-83.

Capone, Alessandro. 2010. What can modularity of mind tell us about the semantics/pragmatics debate? Australian Journal of Linguistics 30:497-520.

Carston, Robyn. 2002. Thoughts and Utterances. The Pragmatics of Explicit Communication. Oxford: Blackwell.

Carston, Robyn. 2004. Relevance theory and the saying/implicating distinction. In Handbook of Pragmatics, eds. Laurence Horn and Gregory Ward, 633-656. Oxford: Blackwell.

Carston, Robyn. 2010. Explicit communication and 'free' pragmatic enrichment. In Explicit Communication. Robyn Carston's Pragmatics, eds. Belén Soria and Esther Romero, 217-285. London: Palgrave Macmillan.

Cummings, Louise. 2005. Pragmatics. A Multidisciplinary Perspective. Edinburgh: Edinburgh University Press.

Davis, Wayne. 1998. Implicature. Intention, Convention, and Principle in the Failure of Gricean Theory. Cambridge: Cambridge University Press.

Grice, H. P. 1975. Logic and conversation. In Syntax and Semantics, Volume 3. Speech Acts, eds. Peter Cole and Jerry Morgan, 41-58. New York: Academic Press.

Grice, Paul. 1989. Studies in the Way of Words. Cambridge, Massachusetts: Harvard University Press.

Haugh, Michael. 2002. The intuitive basis of implicature: relevance theoretic implicitness versus Gricean implying. Pragmatics 12:117-134.

Haugh, Michael. 2008a. The place of intention in the interactional achievement of implicature. In Intention, Common Ground and the Egocentric Speaker-Hearer, eds. Istvan Kecskes and Jacob Mey, 45-85. Berlin: Mouton de Gruyter.

Haugh, Michael. 2008b. Intention and diverging interpretings of implicature in the 'uncovered meat' sermon. Intercultural Pragmatics 5:201-228.

Haugh, Michael. 2008c. Utterance-final conjunctive particles and implicature in Japanese conversation. Pragmatics 18:425-451. 
Haugh, Michael. 2009. Intention(ality) and the conceptualisation of communication in pragmatics. Australian Journal of Linguistics 29:91-113.

Haugh, Michael. 2011. Practices and defaults in interpreting disjunction. In Salience and Defaults in Utterance Processing, eds. Kasia M Jaszczolt and Keith Allan, 193-230. Berlin: Mouton de Gruyter.

Haugh, Michael. 2012. Conversational interaction. In The Cambridge Handbook of Pragmatics, eds. Keith Allan and Kasia M Jaszczolt, 251-274. Cambridge: Cambridge University Press.

Haugh, Michael, and Jaszczolt, Kasia M. 2012. Speaker intentions and intentionality. In The Cambridge Handbook of Pragmatics, eds. Keith Allan and Kasia M Jaszczolt, 87-112. Cambridge: Cambridge University Press.

Heritage, John. 1984. A change of state token and aspects of its sequential placement. In Structures of Social Action, eds. Maxwell J Atkinson and John Heritage, 299-345. Cambridge: Cambridge University Press.

Higashimori, Isao, and Wilson, Deirdre. 1996. Questions on relevance. UCL Working Papers in Linguistics 8:111-124.

Horn, Laurence. 2004. Implicature. In Handbook of Pragmatics, eds. Laurence Horn and Gregory Ward, 3-28. Oxford: Blackwell.

Horn, Laurence. 2012. Implying and inferring. In The Cambridge Handbook of Pragmatics, eds. Keith Allan and Kasia M Jaszczolt, 69-86. Cambridge: Cambridge University Press.

Huang, Yan. 2007. Pragmatics. Oxford: Oxford University Press.

Huitink, Janneke, and Spenader, Jennifer. 2004. Cancelation resistant PCIs. In Proceedings of the ESSLLI 2004 Workshop on Implicature and Conversational Meaning, eds. Bart Geurts and Rob van der Sandt, 8-13. Nancy, France: University of Nijmegen.

Jaszczolt, K. M. 1999. Default semantics, pragmatics, and intentions. In The Semantics/Pragmatics Interface from Different Points of View, ed. Ken Turner, 199-232. Oxford: Elsevier.

Jaszczolt, K. M. 2009. Cancellability and the primary/secondary meaning distinction. Intercultural Pragmatics 6:259-289.

Levinson, Stephen. 1983. Pragmatics. Cambridge: Cambridge University Press.

Levinson, Stephen. 2000. Presumptive Meanings. The Theory of Generalised Conversational Implicature. Cambridge, Mass: MIT Press.

Saul, Jennifer. 2002. Speaker meaning, what is said, and what is implicated. Nous 36:228-248.

Schegloff, Emanuel. 2007. Sequence Organization in Interaction. Cambridge: Cambridge University Press.

Sperber, Dan, and Wilson, Deirdre. 1995. Relevance. Communication and Cognition ( $2^{\text {nd }}$ edn). Oxford: Blackwell.

Vicente, Begona. 1998. Against blurring the explicit/implicit distinction. Revista Alicantina de Estudios Ingleses 11:241-258.

Weiner, Matthew. 2006. Are all conversational implicatures cancellable? Analysis 66:127-130.

Wilson, Deirdre, and Sperber, Dan. 1986. Inference and implicature. In Meaning and Interpretation, ed. Charles Travis, 45-75. Oxford: Basil Blackwell.

Woods, John. 2010. Inference. In The Pragmatics Encyclopedia, ed. Louise Cummings, 218220. London: Routledge. 